\title{
Investigation of the fracture toughness of radio frequency magnetron sputtered Al-Cu-Fe films via white-beam synchrotron radiography/topography
}

\author{
B L French ${ }^{1}$, M J Daniels ${ }^{2}$ and J C Bilello ${ }^{3}$ \\ ${ }^{1}$ Department of Applied Science, College of William and Mary, PO Box 8795, \\ Williamsburg, VA 23187-8795, USA \\ ${ }^{2}$ Formerly with the Center for Nanomaterials Science, Department of Materials Science and \\ Engineering, University of Michigan, 2300 Hayward St., Ann Arbor, MI 48109-2136, USA \\ ${ }^{3}$ Center for Nanomaterials Science, Department of Materials Science and Engineering, \\ University of Michigan, 2300 Hayward St., Ann Arbor, MI 48109-2136, USA
}

Received 1 March 2005

Published 6 May 2005

Online at stacks.iop.org/JPhysD/38/A44

\begin{abstract}
A novel white-beam synchrotron radiography/topography substrate curvature technique has been used to study stress development in situ during annealing of $\mathrm{Al}-\mathrm{Cu}-\mathrm{Fe}$ quasicrystalline and approximant coatings, as well as to image their failure modes in real time. Single crystal Si and sapphire substrates were coated with a $2.55 \mu \mathrm{m}$ precursor coating by RF sputtering from an $\mathrm{Al}_{65} \mathrm{Cu}_{23} \mathrm{Fe}_{12}$ powder composite target and subsequently annealed at $585^{\circ} \mathrm{C}$ while stress and imaging data were acquired. After the initial ramp to the annealing temperature, a stress plateau was reached for coatings on both $\mathrm{Si}$ and sapphire substrates, although the magnitude of the stress plateau was different in each case. A tensile stress developed in the coatings during cooling due to differential thermal expansion between the coating and substrate, allowing for calculation of both the coefficient of thermal expansion and elastic modulus of the film. During cooling, the films exhibited different stress evolution above and below $470^{\circ} \mathrm{C}$, a temperature of interest in $\mathrm{Al}-\mathrm{Cu}-\mathrm{Fe}$ quasicrystal and approximant phase development. The $\mathrm{Al}-\mathrm{Cu}-\mathrm{Fe}$ coating on the Si substrate fractured at approximately $954 \mathrm{MPa}$, while the coating on the sapphire substrate fractured at approximately $431 \mathrm{MPa}$. From these values the fracture toughness was calculated to be 1.9 $\mathrm{MPa} \mathrm{m}^{1 / 2}$ and $0.76 \mathrm{MPa} \mathrm{m}^{1 / 2}$ for the coatings on Si and sapphire, respectively.
\end{abstract}

\section{Introduction}

The beneficial properties of the quasicrystalline structure have been examined extensively, and include exceptional hardness, low coefficients of friction, wear resistance and anticorrosion properties. Many of these properties arise from the aperiodic quasicrystalline structure, which inhibits dislocation movement and electron flow at room temperature. The Al- $\mathrm{Cu}-$ Fe system is perhaps the most well-studied quasicrystalline system, and the region of single phase stability is around $3-5$ at $\%$ [1]. In addition to the quasicrystalline structure, which exists only when annealing is performed above $700^{\circ} \mathrm{C}$, so-called approximant phases are also known to exist below $600^{\circ} \mathrm{C}$. Approximant phases are crystal structures that closely resemble their quasicrystalline counterparts, but exhibit longrange order on length scales of several nanometres. In the $\mathrm{Al}-\mathrm{Cu}-\mathrm{Fe}$ system, the icosohedral phase $(\psi)$ is produced above $700^{\circ} \mathrm{C}$, while a rhombohedral approximant (R-phase) is produced between $450^{\circ} \mathrm{C}$ and $600^{\circ} \mathrm{C}$. The transformation between these two phases was first reported by Bancel [2], and differences between these phases have been examined in other studies $[3,4]$. Due to the similarity in structure, most 
characteristics of the approximant are similar to those of the quasicrystal.

Quasicrystalline and approximant thin films are particularly useful because they mitigate the risk of the brittle nature of these materials. Mechanical properties of bulk materials have been studied at length, but attempts have not been made to determine or analyse the stress development in quasicrystalline or approximant coatings. Yet, because annealing of precursor films is required to effect quasicrystal or approximant phase development, cracking of the film poses the most substantial obstacle to successful implementation of these types of coatings. In this work, a novel radiography/topography technique is used to quantitatively examine stress development in the coatings in an effort to determine how they might be used more effectively. In the past this technique has been successfully implemented to study compression-driven delamination of Ta films [5,6] and tensile failure of CrN coatings [7], both on $\mathrm{Si}$ substrates. The strength of this technique lies in its ability to measure stress in a coating through diffraction topography of the crystalline substrate, while simultaneously recording the morphology of the coating through radiographic contrast contained in the topographic image. Thus, an unambiguous correlation can be made, in real time, between coating failure events and the stress that caused them.

\section{Experiment}

Coatings were produced by RF sputtering from a composite target in a planar magnetron sputter system, using Si (100) and sapphire (0001) wafers as substrates. The pressed powder sputter target was fabricated in the atomic ratio $\mathrm{Al}_{65} \mathrm{Cu}_{23} \mathrm{Fe}_{12}$ [8]. Base pressure, prior to sputtering, was less than $4.8 \times 10^{-5} \mathrm{~Pa}\left(3.6 \times 10^{-7}\right.$ Torr $)$ and neither substrate bias nor heating was used. The samples were passed in front of the sputter target on a rotating, $21.6 \mathrm{~cm}$ radius carousel at a rate of $0.2 \mathrm{rpm}$ with a closest-approach target-to-substrate distance of $3.8 \mathrm{~cm}$. Substrates were cleaned prior to deposition by sputter etching with an $800 \mathrm{~V}$ bias for $10 \mathrm{~min}$ in $0.33 \mathrm{~Pa}$ (2.5 mTorr) argon. Deposition was performed using $0.67 \mathrm{~Pa}$ ( $5 \mathrm{mTorr}$ ) argon and $600 \mathrm{~W}(800 \mathrm{~V})$ target power. The thickness of the resulting coating was measured to be nominally $2.55 \mu \mathrm{m}$ by white light interference microscopy.

The initial stress state of the $\mathrm{Al}-\mathrm{Cu}-\mathrm{Fe}$ coating on silicon was characterized by double crystal diffraction topography (DCDT), a wafer curvature method [9]. The initial stress state of the same coating on sapphire was determined from measuring wafer curvature with the transmission Laue technique described in the next section. Nanoindentation tests were performed on an annealed coating on a Si wafer using a Hysitron TriboIndenter ${ }^{\circledR}$. Fifty indentation tests were performed in a grid configuration on an adherent portion of the film using a Berkovich indenter tip with a trapezoidal load function. The load was applied linearly over $5 \mathrm{~s}$, held for $2 \mathrm{~s}$, and unloaded linearly over $5 \mathrm{~s}$. A maximum load of $500 \mu \mathrm{N}$ was used, and the reduced modulus and hardness were obtained.

Transmission Laue experiments were conducted at the Stanford Synchrotron Radiation Laboratory on the bending magnet beamline 2-2, with $2-40 \mathrm{keV}$ x-rays and a $0.6 \mathrm{mrad}$ horizontal divergence for the spot size used. Films were

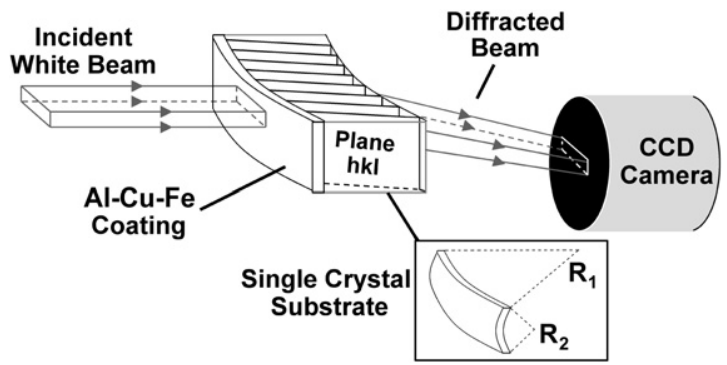

Figure 1. Schematic illustrating the focusing effect of the bent substrate on the incident white beam, and the attendant change in the size of Laue reflection $(h k l)$ observed by the CCD camera. The inset defines the two orthogonal radii of curvature, $R_{1}$ and $R_{2}$, in the horizontal and vertical planes, respectively.

annealed in an apparatus described elsewhere by Zhao et al $[7,10]$ and French and Bilello [5]. This consisted of a heating stage employing four halogen lamps capable of heating the samples to $600^{\circ} \mathrm{C}$, and a charge-coupled device (CCD) x-ray imaging system. The CCD camera had a $20 \mu \mathrm{mpixel}^{-1}$ resolution and an aperture diagonal of $18 \mathrm{~mm}$ with a $3: 4$ aspect ratio. Samples were mounted on the heating stage in transmission Laue geometry such that the beam was normally incident upon the sample surface, away from the sample edges as shown in figure 1. Before annealing, the CCD camera was placed over the (133) reflection for Si substrates, and an in-plane reflection of the $c$-axis sapphire substrates. These reflections were chosen for their convenient trajectory (parallel to the floor) within the experimental set-up. During each anneal, Laue transmission diffraction topography/radiography images were acquired in real time ( 30 frames $^{-1}$ ) with the CCD camera, and also periodically with a frame-grabbing computer program capable of averaging multiple frames for higher-resolution images. The sample-to-camera distance was approximately $30 \mathrm{~cm}$ for all samples, and the incident beam dimensions were nominally $12 \times 5 \mathrm{~mm}^{2}$.

\section{Data analysis}

The derivation of equations used to relate the dimensions of the Laue reflection observed in the CCD camera to the curvature of the substrate is described in detail elsewhere [5]. Only a qualitative discussion of the technique is given here along with expressions needed to calculate the fracture toughness of the coatings.

For a thin film bonded to a sufficiently thin substrate, biaxial film stress bends the substrate such that its curvature can be represented by radii of curvature in two orthogonal planes as seen in the inset of figure 1. Any diffracted beam will undergo a change in cross-sectional shape in the camera plane as curvature is applied to the substrate. This effect is also illustrated in figure 1 . The change in a reflection's dimensions for a given change in substrate curvature is essentially a ray-tracing problem in which the trajectory of four rays, representing the corners of the rectangular diffracted beam, are determined as a function of substrate curvature in two orthogonal planes. Thus, in the transmission Laue geometry of figure 1, a compressive film stress focuses the diffracted beam, reducing the size of the topographic image, while a tensile film stress defocuses the diffracted beam, enlarging the size 
of the topographic image. The measured quantities needed to determine the film stress are the dimensions of the incident beam, the sample-to-camera distance, and the dimensions of the topographic images recorded by the CCD camera. It is also pertinent to know the incident beam divergence (both horizontally and vertically), the magnitude of any pre-existing substrate curvature, and the indices of the observed reflection. The resolution of this technique is limited by the $20 \mu \mathrm{m} \mathrm{pixel}^{-1}$ resolution of the CCD camera, not by the effective 'angular source size' which typically limits spatial resolution in $\mathrm{x}$-ray topographs. Using the current experimental configuration, the $20 \mu \mathrm{m}_{\text {pixel }}{ }^{-1} \mathrm{CCD}$ camera resolution corresponds to a $1 \mathrm{~km}$ detection limit for the substrate radius of curvature.

Theoretically the images can be analysed to determine the substrate curvature in both orthogonal directions; however, in these experiments, the selected reflection had little sensitivity to the substrate curvature in one direction $\left(R_{2}\right.$ in the inset of figure 1), due to the orientation of the diffracting planes. The trajectory of the $\mathrm{Si}$ (133) reflection used in these experiments was completely contained in the horizontal plane, and thus was mainly sensitive to radius of curvature $R_{1}$. The incident beam had a smaller height than width, further reducing the 'optical leverage' in that direction. For isotropic stress in the plane of the film, measurement of $R_{1}$ is sufficient to compute the entire stress state. In the case of an anisotropic stress, use of $R_{1}$ alone makes it impossible to calculate the directions of the principal stresses in the coating, but the computed stress remains accurate along the direction in the sample described by $R_{1}$. In this study stress anisotropy was not evaluated since only $R_{1}$ was measured, but in future work its effect will be considered by observing a Laue reflection with sensitivity to both $R_{1}$ and $R_{2}$.

Changes in the topographic image size are first related to changes in the substrate radius of curvature $\left(R_{1}\right)$ using an equation of the following form:

$$
\begin{aligned}
R_{1}= & \frac{w}{2}\left(\operatorname { s i n } \left(\frac{1}{4} \arcsin \left(\frac{-K \cos 4 \alpha}{\sqrt{K^{2}+1}}\right)\right.\right. \\
& \left.\left.-\frac{1}{4} \arctan K+\frac{1}{2} \phi\right)\right)^{-1} .
\end{aligned}
$$

Here, $w$ is the width of the incident beam, $K$ is proportional to the change in the topographic image dimensions and the sample-to-camera distance, $\alpha$ is the angle between the incident beam and the projection of the diffraction vector onto the horizontal plane and $\phi$ is the horizontal divergence of the incident beam. This equation computes the radius of curvature necessary to produce the observed image size from an incident beam of known dimensions and divergence. The stress in the film is determined from the radius of curvature using the modified Stoney equation

$$
\sigma=\frac{E_{\mathrm{s}}\left(h_{\mathrm{s}}\right)^{2}}{6 h_{\mathrm{f}}\left(1-v_{\mathrm{s}}\right)}\left(\frac{1}{R}-\frac{1}{R_{0}}\right),
$$

where $\sigma$ is the film stress, $E_{\mathrm{S}}$ is the substrate elastic modulus, $v_{\mathrm{s}}$ is the Poisson ratio of the substrate, $R_{0}$ is the initial radius of curvature, and $h_{\mathrm{s}}$ and $h_{\mathrm{f}}$ are the substrate and film thickness, respectively $[11,12]$. It should be noted here that the instantaneous stress calculated by equation (2) is relative to the initial stress in the film, so the initial stress had to be determined first by DCDT [9].

For given annealing conditions and a known film modulus, a plot of stress versus temperature (see figure 4) can be used to calculate the coefficient of thermal expansion (CTE), fracture strength and fracture toughness of the film. Assuming that only CTE mismatch stress is acting on the film, and that the film only undergoes linear elastic strain, the slope of the cooling portion of this plot is expressed by

$$
\frac{\Delta \sigma}{\Delta T}=\frac{E_{\mathrm{f}}}{1-v_{\mathrm{f}}}\left(\alpha_{\mathrm{s}}-\alpha_{\mathrm{f}}\right),
$$

where $E_{\mathrm{f}}$ is the elastic modulus of the film, $v_{\mathrm{f}}$ is the Poisson ratio of the film and $\alpha_{\mathrm{s}}$ and $\alpha_{\mathrm{f}}$ are the CTE of the substrate and film, respectively. In this study two different substrates were used, so equation (3) can be solved for both $\alpha_{\mathrm{f}}$ and $E_{\mathrm{f}}$, assuming the coatings on each substrate are identical.

For a catastrophic failure with almost no yielding beforehand, the fracture strength of the material is simply the stress at fracture, as observed by the real-time transmission topography/radiography images and a sharp relaxation in the stress (e.g. point ' 4 ' in figure 2). This value alone provides a basis for comparison between films, but the fracture toughness is also of interest for hard, and often brittle, wear coatings. For a film-substrate couple with elastic modulus mismatch, and assuming the film cracks extend from the film's free surface to exactly the film-substrate interface, the critical energy-release

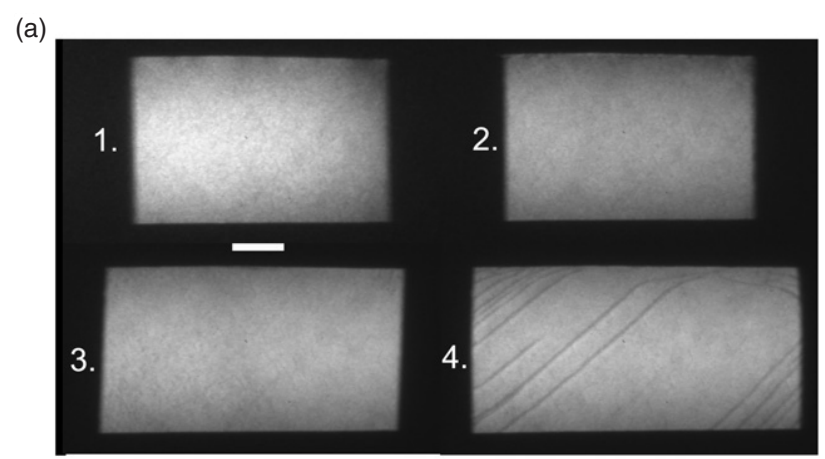

(b)

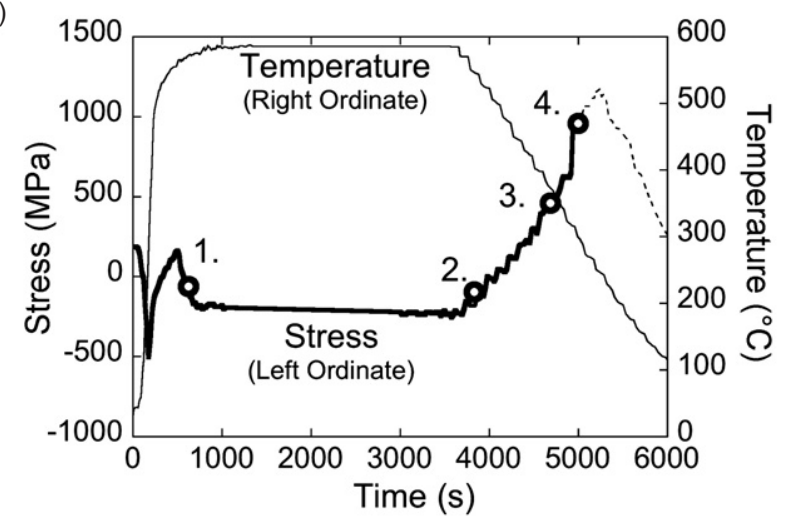

Figure 2. Plot of stress and temperature versus time during annealing of an $\mathrm{Al}-\mathrm{Cu}-\mathrm{Fe}$ coating on a $\mathrm{Si}(100)$ substrate. The stress data were calculated from the topographic image widths using the stress determination method described in this work and in [5]. Above the plot, Si (133) topographs are shown from various points in the thermal cycle. The white scale bar corresponds to $2 \mathrm{~mm}$. 
rate necessary for cracking, $G_{\text {critical }}$, is

$$
G_{\text {critical }}=\frac{1}{2} \frac{\sigma^{2} h_{\mathrm{f}}\left(1-v_{\mathrm{f}}\right)}{E_{\mathrm{f}}} \pi g\left(E_{\mathrm{f}}, E_{\mathrm{s}}\right),
$$

where $\sigma$ is the stress in the film at the point of fracture, and $g\left(E_{\mathrm{f}}, E_{\mathrm{s}}\right)$ is a parameter tabulated by Beuth [13]. For the film-substrate couples considered in this study, the function $g\left(E_{\mathrm{f}}, E_{\mathrm{s}}\right)$ approaches unity. Lastly, the mode-1 fracture toughness of the film, $K_{1 \mathrm{C}}$, is related to $G_{\text {critical }}$ by $[14,15]$

$$
G_{\text {critical }}=\frac{K_{1 \mathrm{C}}^{2}}{E_{\mathrm{f}}}
$$

\section{Results and discussion}

\subsection{X-ray imaging}

Figures 2(a) and 3(a) each depict four topographic/radiographic images from annealing of $\mathrm{Al}-\mathrm{Cu}-\mathrm{Fe}$ coatings on silicon and sapphire substrates, respectively. These images are each averages of 16 video frames to achieve higher resolution and reduce noise. Images 1, 2 and 3 in figure 2(a) are featureless, as would be expected for a pristine film on a defect-free substrate. Upon cooling from the anneal temperature, however, severe cracking of the film becomes evident as bands appearing at $45^{\circ}$ angles to the edge of image 4 in figure 2(a). The radiographic nature of this contrast has been confirmed by comparing multiple $\mathrm{Si}$ reflections in a Laue pattern.

(a)

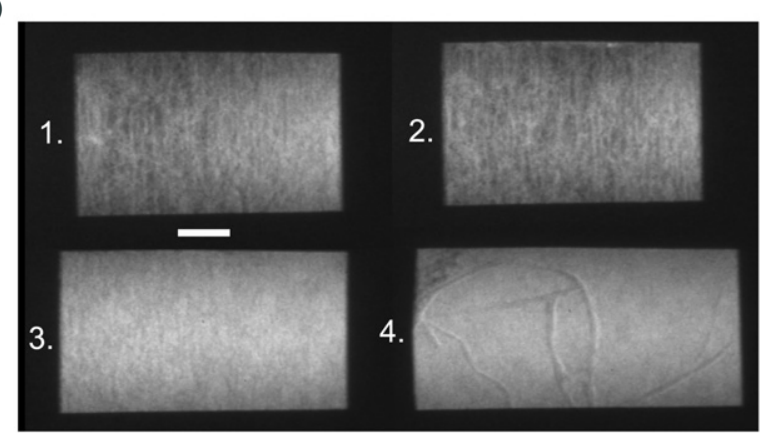

(b)

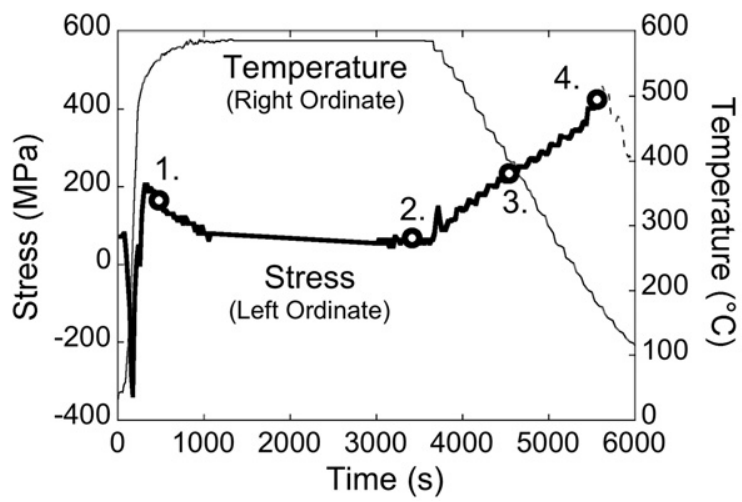

Figure 3. Plot of stress and temperature versus time during annealing of an $\mathrm{Al}-\mathrm{Cu}-\mathrm{Fe}$ coating on a sapphire (0001) substrate. The stress data were calculated from the topographic image widths using the stress determination method described in this work and in [5]. Above the plot, topographs are shown from various points in the thermal cycle. The white scale bar corresponds to $2 \mathrm{~mm}$.
In images 1 and 2 of figure 3(a), the topographs are not featureless due to dislocation networks in the sapphire substrate. The topographic nature of this contrast has been confirmed by comparing multiple sapphire reflections in a Laue pattern. In image 3 of figure 3(a) the topograph appears featureless, but in fact the image has been defocused due to substrate curvature to the point that the defects can no longer be observed. As in the images of figure 2(a), this coating cracks after sufficient cooling, as evidenced by the bands in image 4 of figure 3(a). The cracking in this sample does not develop in orderly $45^{\circ}$ bands, but instead appears in random directions. This discrepancy could indicate different texturing is present in the films grown on each substrate.

\subsection{Stress evolution}

The stress and temperature of the $\mathrm{Al}-\mathrm{Cu}-\mathrm{Fe}$ coatings during annealing are shown in figures $2(b)$ and $3(b)$. Fluctuations in the stress state early in the thermal cycle were believed to originate from CTE mismatch, different heat capacities, and from the thermal gradient between the film and substrate as the couple reached an equilibrium temperature. A plateau level of stress was observed for the majority of the test, and the magnitude of this plateau was dependent on the substrate type. A significant change in stress due to diffusion accommodation was not observed, as evidenced by the nearly horizontal slope of the plateau region in figures $2(b)$ and $3(b)$. Upon cooling from the anneal temperature, large tensile stresses developed as a result of CTE mismatch between the coating and substrate, ultimately cracking the film. A dashed line is used to represent the stress after the first observed fracture since the coating is no longer continuous.

In figure 4, stress and temperature data points from the cooling portions of figures $2(b)$ and $3(b)$ were plotted against each other and subsequently used to calculate the CTE of the films. A linear relationship is evident in figure 4, but the slope of this relationship changed in the temperature range of $470-500^{\circ} \mathrm{C}$ for $\mathrm{Al}-\mathrm{Cu}-\mathrm{Fe}$ coatings on both substrates. This temperature range has been shown to be critical for rhombohedral approximant phase development [16, 17]. Development of the rhombohedral approximant only occurs at

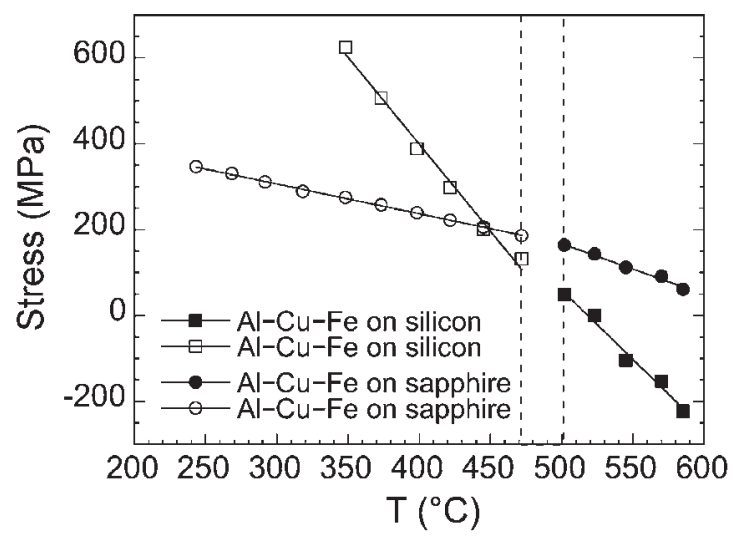

Figure 4. Stress versus temperature data for $\mathrm{Al}-\mathrm{Cu}-\mathrm{Fe}$ coatings on $\mathrm{Si}$ and sapphire substrates. Closed symbols represent the portion of the cooling curve in which diffusion is expected to affect the linearity of this plot. Open symbols represent a lower temperature portion of the cooling curve in which diffusion should be minimal. 
temperatures greater than $450^{\circ} \mathrm{C}$, and sufficient grain growth on the order of minutes has only been observed at temperatures around $515^{\circ} \mathrm{C}$ [16]. Prior work has shown a distinct change in the slope of the thermal diffusivity of this phase at about $500^{\circ} \mathrm{C}$ [18]. A brittle-to-ductile transition has also been observed in the temperature range $450-487^{\circ} \mathrm{C}$ [19]. The change of slope in the stress-temperature data in figure 4 appears to be a consequence of the change in thermal diffusivity, and the anticipated brittle-to-ductile transition. However, if the high and low temperature regimes are assumed to correspond to regimes of high thermal diffusivity (high ductility) and low thermal diffusivity (low ductility), respectively, then corresponding changes in the stress-temperature data would also be anticipated. A transition to a regime of low thermal diffusivity during cooling should cause an increase in the slope of the stress-temperature data as the film is no longer able to accommodate the substrate by a diffusional mechanism. A subtle increase in the slope of this graph was observed for the $\mathrm{Al}-\mathrm{Cu}-\mathrm{Fe}$ coating on $\mathrm{Si}$ below $470^{\circ} \mathrm{C}$, but a reduced slope was observed below $470^{\circ} \mathrm{C}$ for the coating on sapphire. The change from ductile-to-brittle behaviour is the most readily available explanation for this change, but the coating on the sapphire substrate does not show the expected increase in the slope of the stress-temperature plot. The role of yielding has not been thoroughly examined in interpreting these results, although the yield stress is substantially greater than the stress present between $400^{\circ} \mathrm{C}$ and $470^{\circ} \mathrm{C}$, suggesting that it is not a significant factor at these temperatures.

\subsection{Microstructure}

Coatings on polycrystalline alumina substrates from the same deposition lot were annealed ex situ, under the same conditions as samples in this work, to examine microstructure development. A similar attempt to analyse the coatings from the radiography/topography experiments indicated a high degree of texturing, obscuring the picture of phase development caused by annealing [20]. This texturing may have been a result of the single crystal substrate used (and nucleation of the quasicrystalline approximant on this substrate), or the plateau stress level which existed during annealing. Instead, these ex situ anneals give a more accurate representation of the phases present as a result of thermal treatment. The as-deposited coating on alumina is amorphous or nanoquasicrystalline [17], as seen in the diffraction pattern in the lower half of figure 5. At a thickness of less than $3 \mu \mathrm{m}$, it was anticipated that a substrate contribution $(\alpha)$ would be present. The annealed coating (shown in the upper half of figure 5), subjected to the same annealing conditions used during the radiography/topography experiments, showed a complete conversion to the R-phase, or rhombohedral structure. The presence of a small amount of $\beta$-phase, an aluminium-deficient impurity often found in $\mathrm{Al}-\mathrm{Cu}-\mathrm{Fe}$ coatings due to preferential aluminium oxidation, was also noted between the two prominent R-phase peaks.

\subsection{Mechanical properties}

From the stress data in figures $2(b)$ and $3(b)$, the fracture strengths of $\mathrm{Al}-\mathrm{Cu}-\mathrm{Fe}$ coatings on $\mathrm{Si}$ and sapphire substrates were found to be $954 \mathrm{MPa}$ and $431 \mathrm{MPa}$, respectively. The

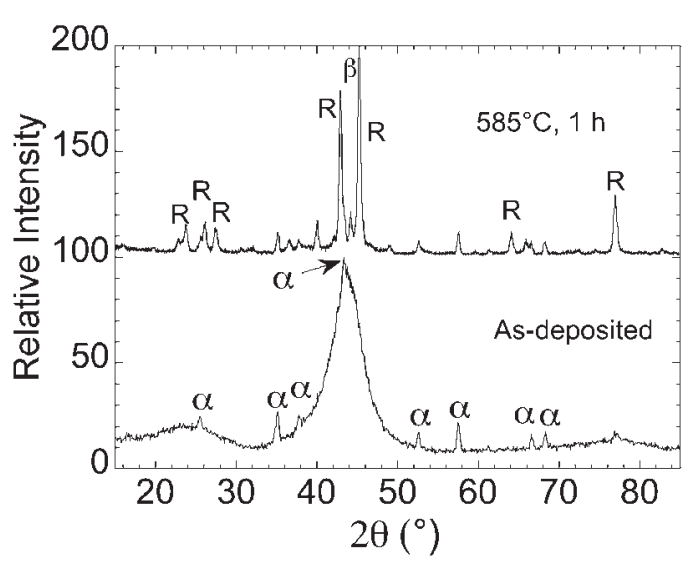

Figure 5. Phase development in an $\mathrm{Al}-\mathrm{Cu}-\mathrm{Fe}$ coating on a polycrystalline alumina substrate annealed ex situ. The annealed sample was subjected to the same temperature, for the same period of time, as the coatings annealed on single crystal substrates in this work.

slight rise in stress observed after fracture, before significant relaxation occurred, is explained by the inverse relationship between minimum crack separation and stress in the coating [21]. Thus, the maxima of the dashed lines in figures $2(b)$ and $3(b)$ represent the points at which the total area of film in which stress has been relaxed by cracking is greater than the total area of islands of stressed, continuous film. Following the analysis procedure outlined in section 3 , the fracture toughness, elastic modulus and CTE were derived from the cooling curves in figure 4 . The slope of the low-temperature portion of each curve $\left(-3.187 \mathrm{MPa}^{\circ} \mathrm{C}^{-1}\right.$ and $-0.698 \mathrm{MPa}^{\circ} \mathrm{C}^{-1}$ for coatings on $\mathrm{Si}$ and sapphire, respectively) was substituted into equation (3) to yield two expressions for the unknown elastic modulus and CTE of the coating. Substituting $\alpha_{\mathrm{Si}}=$ $2.6 \times 10^{-6}{ }^{\circ} \mathrm{C}^{-1}, \alpha_{\text {sapphire }}=8.4 \times 10^{-6}{ }^{\circ} \mathrm{C}^{-1}$ and $v_{\mathrm{f}}=0.23$, the films' elastic modulus was found to be $336 \mathrm{GPa}$, and the CTE to be $10.0 \times 10^{-6}{ }^{\circ} \mathrm{C}^{-1}$. To check the validity of these results, the reduced modulus obtained from nanoindentation of the coated $\mathrm{Si}$ was converted into an elastic modulus of $173 \mathrm{GPa}$, a factor of 2 smaller than that calculated from the cooling curves. This value is almost identical to the value of $168 \mathrm{GPa}$ reported by Takeuchi [22] for bulk icosohedral $\mathrm{Al}-\mathrm{Cu}-\mathrm{Fe}$ quasicrystals. Analysis of the cooling curves with equation (3) required the assumption that the films on each substrate were identical, which is clearly not the case given the dramatic difference in fracture behaviour. The difference in sign and magnitude of stress in the plateau region during annealing at $585^{\circ} \mathrm{C}$ could have caused preferential microstructure development, leading to the observed discrepancies. If the elastic modulus obtained from nanoindentation is substituted into equation (3), the CTE is found to be $\alpha_{\mathrm{f}}=17.0 \times 10^{-6}{ }^{\circ} \mathrm{C}^{-1}$ for the coating on Si. This seems more reasonable for a film that is 65 at $\% \mathrm{Al}$, since Al has a CTE of $23.1 \times 10^{-6}{ }^{\circ} \mathrm{C}^{-1}$.

Using equation (4), the fracture strength, and the elastic modulus determined by nanoindentation, the energy release rate at the point of fracture was found to be $20.44 \mathrm{~J} \mathrm{~m}^{-2}$ for the film on Si. This quantity was not computed for the film on sapphire, since its modulus was obviously different from that of the film on $\mathrm{Si}$, and therefore unknown. Using equations (4) and (5), the fracture toughness was calculated to be $1.9 \mathrm{MPa} \mathrm{m}^{1 / 2}$ and $0.76 \mathrm{MPa} \mathrm{m}^{1 / 2}$ for the coatings on $\mathrm{Si}$ 
and sapphire, respectively. The value of fracture toughness could be calculated for the film on sapphire despite the lack of knowledge about this film's elastic modulus, since substitution of equation (4) in equation (5) cancels out this term. These values compare favourably with fracture toughness values determined by Köster et al [23] and Lee et al [24] of $1.64 \mathrm{MPa} \mathrm{m}^{1 / 2}$ and $1.28 \mathrm{MPa} \mathrm{m}^{1 / 2}$, respectively, for bulk quasicrystalline samples. It should be noted, however, that in the latter study the sample contained $25 \%$ porosity, suggesting an artificially low fracture toughness may have been obtained. The results are nevertheless encouraging.

\section{Conclusions}

The stress evolution and failure behaviour of $\mathrm{Al}-\mathrm{Cu}-\mathrm{Fe}$ rhombohedral approximant films (R-phase) were investigated in situ during annealing at $585^{\circ} \mathrm{C}$ for $1 \mathrm{~h}$, to provide further insight into the failure mechanism of quasicrystalline approximant coatings. During annealing, a plateau level of stress was observed, and the magnitude of the observed stress varied between films on the two substrates. Upon cooling, a tensile stress developed in the coatings, ultimately leading to fracture (via cracking) at $954 \mathrm{MPa}$ and $431 \mathrm{MPa}$ for coatings on $\mathrm{Si}$ and sapphire substrates, respectively. Using these values, the mode- 1 fracture toughness was calculated to be 1.9 $\mathrm{MPa} \mathrm{m}^{1 / 2}$ and $0.76 \mathrm{MPa} \mathrm{m}^{1 / 2}$ for the respective coatings on $\mathrm{Si}$ and sapphire. These values are within a factor of 2 from fracture toughness values previously reported for bulk quasicrystalline samples. Stress and temperature values from the pre-cracked portions of tensile stress development were plotted to show the relationship between these two quantities, and to determine the CTE and elastic modulus of the film. Two distinct slopes were observed in the stress versus temperature plot, corresponding to regimes of high and low thermal diffusivity, or a ductile-to-brittle transition during cooling. Using the slope of the stress versus temperature data, the elastic modulus and CTE of these quasicrystalline approximant coatings were calculated to be $336 \mathrm{GPa}$ and $10.0 \times 10^{-6}{ }^{\circ} \mathrm{C}^{-1}$, respectively.

\section{Acknowledgments}

This research was supported by ARO under grant number DAAD19-02-1-0335, DARPA Grant F0011539 and USDoE
Proposal no. 2592MP for synchrotron beam time and facilities at SSRL. Data analysis by $\mathrm{K}$ Boenke and nanoindentation performed by $\mathbf{J}$ Forte of Hysitron, Inc. are also gratefully acknowledged.

\section{References}

[1] Gayle F W, Shapiro A J, Biancaniello F S and Boettinger W J 1992 Metall. Trans. A 232409

[2] Bancel P A 1989 Phys. Rev. Lett. 632741

[3] Audier M, Brechet Y, DeBoissieu M, Guyot P, Janot C and Dubois J M 1991 Phil. Mag. B 631375

[4] Dubois J M, Kang S S, Archambault P and Collert B 1993 J. Mater. Res. 838

[5] French B L and Bilello J C 2003 J. Appl. Phys. 94224

[6] French B L and Bilello J C 2004 Thin Solid Films 44691

[7] Zhao Z B, Rek Z U and Bilello J C 1999 Phil. Trans. R. Soc. Lond. A 3572681

[8] Daniels M J, King D, Fehrenbacher L, Zabinski J S and Bilello J C 2005 Surf. Coat. Technol. 19196

[9] Kuo C L, Emamian M and Bilello J C 1984 J. Appl. Phys. 55375

[10] Zhao Z B, Hershberger J, Rek Z U and Bilello J C 1998 Mater. Res. Soc. Symp. Proc. $\mathbf{5 0 2} 163$

[11] Stoney G G 1909 Proc. R. Soc. Lond. Ser. A 82172

[12] Hoffman D W 1965 Physics of Thin Films vol 3, ed G Haas and R E Thun (New York: Academic) p 211

[13] Beuth J L 1992 Int. J. Solids Struct. 291657

[14] Hu M S, Thouless M D and Evans A G 1988 Acta Metall. 36 1301

[15] Zhao M-H, Fu R, Lu D and Zhang T-Y 2002 Acta Mater. 50 4241

[16] Bonasso N and Pigeat P 2004 J. Non-Cryst. Solids 334-335 509

[17] Widjaja E J and Marks L D 2003 Thin Solid Films 44163

[18] Dubois J M, Kang S S, Archambault P and Colleret B 1993 J. Mater. Res. 838

[19] Giacometti E, Baluc N and Bonneville J 1998 19th Riso Int Symp. on Materials Science: Modelling of Structure and Mechanics of Materials from Microscale to Product ed J V Carstensen et al (Riso National Laboratory, Denmark) pp 267-72

[20] Daniels M D, French B L, King D and Bilello J C 2003 Mater. Res. Soc. Symp. Proc. $\mathbf{7 5 0} 243$

[21] Thouless M D, Olsson E and Gupta A 1992 Acta Metall. Mater. 401287

[22] Takeuchi S 1999 Mater. Res. Soc. Symp. Proc. 553283

[23] Köster U, Liu W, Liebertz H and Michel M 1993 J. Non-Cryst. Solids 153-154 446

[24] Lee S M, Kim B H, Kim S H, Fleury E, Kim W T and Kim D H 2000 Mater. Sci. Eng. 294-29693 